\title{
The Pedagogical Strategies for Online Music Learning of Instrumental Lessons in Higher Education
}

\author{
Kuo-Ying Lee ${ }^{1, *}$
}

\author{
${ }^{1}$ College of Music, Zhaoqing University \\ kuoyinglee@hotmail.com
}

\begin{abstract}
With the increasing growth of modern technology, more and more educators incorporate innovative equipment in their classes for advanced educational approaches. Particularly, the physical courses are limited or prohibited during the COVID-19 pandemic, and therefore the online courses became mandatory for the schools. The online course provides a different experience from the physical class, but in the meanwhile, it takes more energy and preparation for educators to manage the class. Music learning in higher education is a multidisciplinary process that associates with various aspects of history, literature, fine arts, social culture, and psychology. The distance learning of instrumental lessons has displayed several problems and challenges compared with the traditional learning pathways. In order to make a better course delivery, this study will propose the pedagogical strategies for online instrumental music learning in higher education.
\end{abstract}

\section{Keywords: Pedagogical Strategies, Online Music learning, Online instrumental lessons}

\section{INTRODUCTION}

The regular way of perceiving knowledge for college students is attending classes on campus. The historical references indicate that online technology has begun to be applied in music education since the late 1990s, particularly during the years from 1989 to 1995 [1]. Although the published literature mentions the application of technology in distance learning, there is little scholarly research concerning the pedagogical strategies for online courses of instrumental lessons. It is because that the computer assistive devices do not convey as complete information as received in the physical classes. Nevertheless, the aid of computer-based technology in music education is gradually a widespread approach, and it develops a feasible system.

\subsection{The Goal of Online Music Courses}

The definition of an online course is very similar to the conceptualization of e-learning, a term used to indicate a computer-based learning management system that is also called distance learning. The online courses are often combined along with the physical courses for criteria of some programs in universities and colleges, providing the learning opportunity for people with scheduling limits and financial difficulties. Music learning is highly connected with the context of history, literature, aesthetics, and multi-cultures, and an online music course develops a collaborative learning environment with diverse resources of audio and video learning materials. The delivery of an online music course becomes a leading trend influenced by the highly technological progression in all aspects of life. Although the present online teaching practices rarely involve the subject of instrumental learning, the distance learning models of instrumental playing class are gradually blended along with the physical classes due to the pandemic environmental changes. In order to make the study program more accessible and manageable, the instructors make use of online music courses to decrease the risk of face-to-face infection in the physical classes. Distance learning in music education also broadens the educational market by increasing the number of online users without age, national or accommodation limitations. Most recently, the claiming of life-time learning becomes popular due to the compelling force of internet service as well. On the other hand, the deficiency of learning perception in the online music courses is presented. Online pedagogy could be overly leaning to the aspects of a computer-based application. Besides, establishing a community within the online environment is a different experience from how it is working in the traditional instructional format. The learners do not always find a 
sense of belonging in the computerized system. In other words, innovative technologies solve some existing problems but also come up with discomfort in transiting from traditional teaching behavior to adoption of technological equipment. The following paragraphs will discuss the details.

\subsection{Overview of the Literature}

Researches pertaining to online music learning can be divided into two primary categories. One is the type of historical studies discussing the framework of integrative technology in distance learning [2]. The secondary type focuses on the exploration of pedagogical approaches for online music courses. Chronologically, the publication of online music learning displays four dimensions that respectively address technical, organizational, pedagogical, and sociocultural aspects [3]. In the early 2000s, particularly from 2002 to 2004, the relevant studies mainly emphasize the general concept and description of online music courses and their practice. Since 2007, studies of online music learning have turned to explore the case studies and specific models of the educational application. According to the research made by Shih et al who observed more than 400 papers from the scientific indexed journals, the most frequently discussed topics in light of online learning in the early 2000s are titles concerning environment-interactive learning environment, instructional approachcollaborative learning, and metacognition-perception and awareness. [4].

According to the current scholarly findings, the earliest setting of distance learning is the correspondence courses through the mail. Later on, the mode of distance learning was shifted and delivered by interactive television and the internet [5]. With the technological development in the website service, the online music course turned into a systematic program that offered a series of steady class assignments and examinations. Scholars have pointed out that the application of technology in music learning and teaching is an integral part of human evolution that caused by the environmental force, which also influences the way how we make and understand music [6]. The first online music graduate study program appeared in 2005, which functioned asynchronously. Afterward, the synchronous music education program was also open and much more available for most universities in 2008, at the time the scholars began to analyze the efficiency and satisfaction of both school faculty and students [7]. In 2010, Groulx and Hernly proposed that there was substantial growth in online music programs for graduate music studies, and they made a comparative analysis of nine graduate music education programs available online in 2008 at Auburn University, Boston University, East Carolina University, Ohio University, Stephen F. Austin University, the University of Hawaii at Manoa, the University of South
Florida, the University of Montana, and the University of Southern Mississippi [8]. After 2010, scholars began to investigate the educational perception of online music education by collecting data from interviews, online discussion boards, and online surveys through email [9] [10].

Overall, the majority of the scholarly researches concerning music distance learning focused on the integration of technology, and there is still much more to be learned from the diversity of online institutional programs. The study of online instrumental lessons can be a new standpoint of evaluating the influence and strategies for the rapid technological advancement in educational programs.

\subsection{Instrument Teaching Via Internet}

The most traditional approach of instrumental teaching class documented in the domains of music education is the one-by-one lesson, by which the educator constructs a learning pattern to observe and correct the learner's behaviours. When a certain number of students reach a higher level, the teacher moves on to gather them together for an intermediate level of group classes. For an undergraduate student who majors in music in a college, the playing skill of at least one type of instrument is fundamental and necessary, and consequently, the pedagogical strategies for online instrumental course open a new field of study in music education. In contrast with the music history or music theory classes which emphasize the comprehension of knowledge, the process of learning how to play the instrument requires more specific instructions with respect to the teaching practice. The instrumental teaching requires infinite sensitivity and adjustability of music instructors to make the complex manipulation as the music content contains both intellectual knowledge and skill training. However, distance learning results in benefits and challenges simultaneously. Regarding the advantages, the perception of online lessons resolves the problem of relocation for students and instructors. Besides, the online class is convenient, cost-effective, and less time-consuming. On the negative side, the audio effect and the speed of the $\mathrm{Wi}$ Fi could affect the course quality. In consideration for a better pedagogical setting, the technical perspectives of both computer literacy and performing skill should be considered in the teaching practice. A better understanding of how the integration of digital technology and internet platforms enhances the pedagogical approach is useful to music instructors and music learners. As a result, it is significant to experiment with various facilities for online teaching.

\section{TECHNOLOGICAL PERSPECTIVES}

Learning tools are essential for a better perception of music education via internet service, and the features of 
online instrumental courses regularly involve the webbased service as well as various platforms. Within the scope of technology, the internet provides many resources in support of online music learning.

\subsection{Online Music Resources and Platforms}

Professional web platforms take important roles in online music education. For example, massive online open course (MOOC) functions as the most studied online modality which possesses networks of distributed online resources, and well-structured learning pathway resources centralized on MOOCs platforms [11]. In addition to MOOC, other online music resources of the live broadcasting website with screen sharing function such as Skype, Zoom, Google Hangouts, and Whereby are available and prominent. With an examination of each of these five communication tools mentioned above, a comparative analysis of their fundamental functions is described below in table one:

Table1. Comparison of five communication tools

\begin{tabular}{|c|c|c|c|c|}
\hline Brand & Skype & Zoom & $\begin{array}{l}\text { Google } \\
\text { Hangout } \\
\text { s }\end{array}$ & Whereby \\
\hline $\begin{array}{l}\text { Adaptive } \\
\text { devices }\end{array}$ & $\begin{array}{l}\text { Compute } \\
r \\
\text { Tablet } \\
\text { Mobile }\end{array}$ & $\begin{array}{l}\text { Compute } \\
r \\
\text { Tablet } \\
\text { Mobile }\end{array}$ & $\begin{array}{l}\text { Compute } \\
\text { r } \\
\text { Tablet } \\
\text { Mobile }\end{array}$ & $\begin{array}{l}\text { Compute } \\
r \\
\text { Tablet } \\
\text { Mobile in } \\
\text { Android }\end{array}$ \\
\hline $\begin{array}{l}\text { Students } \\
\text { account } \\
\text { needed }\end{array}$ & Yes & $\begin{array}{l}\text { No } \\
\text { with link }\end{array}$ & $\begin{array}{l}\text { No } \\
\text { with link }\end{array}$ & $\begin{array}{l}\text { No } \\
\text { with link }\end{array}$ \\
\hline $\begin{array}{l}\text { Record } \\
\text { calls }\end{array}$ & available & available & available & $\begin{array}{l}\text { available } \\
\text { in paid } \\
\text { version }\end{array}$ \\
\hline $\begin{array}{l}\text { Group } \\
\text { call }\end{array}$ & $\begin{array}{l}\text { Up to } 50 \\
\text { people }\end{array}$ & $\begin{array}{l}3 \text { people } \\
\text { and } \\
\text { above } \\
\text { with } 40 \\
\text { minute in } \\
\text { free } \\
\text { version }\end{array}$ & $\begin{array}{l}\text { Up to } 25 \\
\text { people }\end{array}$ & without \\
\hline
\end{tabular}

The video calling system and the playing back function of communication tools help the learner to watch back when they need to review the class. To take good advantage of the platform, a music educator usually also has to be familiar with additional learning apps for a better class delivery. For instance, apps of virtual piano provide beginners with a basic scheme of the piano keyboard that has a range of one or more than one octave with movable scrolling bottom to shift the register of the octave. Moreover, the apps of electronic turner and apps of metronome are applicable in the virtual classroom for pedagogical aids.

A great number of music online libraries such as Rilm and Naxos provide plenty of digital music sources that can be shared through distance learning. Other than the technological educational apps and platforms, the social media programs can be used to build up a peer community of class for further discussion. The multiple selections of online platforms make the music institutions competitive. However, not all modern technological types of equipment are flawless for the users. The limitation of a computer system or the conflict between different programs of software sometimes happens and leads to technical problems. The technological advancement creates innovative teaching practice, but socially it does not work the same as the in-person classes. The educators could spend much time on the manipulation of computerbased works for class preparation without paying enough attention to the mental work in the teaching process. To make a closer investigation, we can discover the existing challenges of online instrumental teaching.

\subsection{Challenges of Online Instrumental Teaching}

There are several drawbacks in the online instrumental teaching that need to be improved. First, many educators encounter the same problem resulted from the lack of communication between students and teachers in distance learning. Unlike the theoretical knowledge, the performing skills of an instrument do not always fit in the template-based document preparation in distance learning. Moreover, many versatile physical gestures and breathings of performing skills are not clearly presented through the internet. The missing interaction of body language may cause misunderstanding and false perception of music instructions. The distortion of sound through the computing devices can also make the teaching process disorganizing and inefficient. Furthermore, the learner's concentration of mind is sometimes untraceable due to the lagging of time, which happens frequently when the computer system runs into updating status. A positive outcome of an instrumental playing could sound no different from the negative example in the online course concerning the sonorous effect in a virtual class. When a teacher has to demonstrate in class, the online delivery might fail in presenting the important musculoskeletal feature of certain motions. It is even more unpractical to have the instrumentalist play ensemble together through distance learning mode. However, collaboration is a very important part of the learning process of instrumental playing. Groups such as orchestra, winds, or string quartet have to learn the music together. By far, there is no real online replacement for physical courses of ensemble activity. As a result, one can assume that the online courses are not fully feasible and suitable in terms of the diverse format of music performance. To make better music instructions and perceptions, establishing good systematic pedagogical strategies can temporarily make up for the negative outcome of distance learning. 


\section{PEDAGOGICAL STRATEGIES}

Generally, the overall pedagogy of the distance learning in the music field is still lack of supportive experience, and particularly, instrumental teaching has more challenges in course design compared with other subjects of music classes. The teaching techniques of instrumental playing are different from individual to individual, depending on the context of materials and each student's perception. Nevertheless, it is noteworthy to notice that the learning objectives are mostly the same no matter the course is taught via internet or in the traditional format. Accordingly, setting up good pedagogical strategies is necessary for the online instrumental lessons. To propose useful suggestions for online instrumental teaching, the author comes up with principles from the perspectives of technical, interactive, and problem-based learning (PBL) views. The proposed strategies are organized in three stages.

\subsection{Technical Aspect}

First of all, because the quality of online instrumental class strongly associates with the application of the microphone, camera, and headset, the guaranty of wellprepared equipment is mandatory. The author interviewed 23 music college students in the piano majors with the same fair value of equipment, collecting and summarizing their opinion of what is the most often seen technical problem when taking online instrumental classes. It turned out the result as listed in the following table:

Table2. Top 5 most frequently seen technical problems:

\begin{tabular}{l}
$\begin{array}{l}\text { The top five most frequently seen technical } \\
\text { problems of online instrumental class }\end{array}$ \\
\hline $1 . \quad$ Sound is behind the scene, lagging problem \\
$\begin{array}{l}\text { 2. Fast notes from the playing are inaudible, } \\
\text { blurring sound }\end{array}$ \\
$\begin{array}{l}\text { 3. The low frequency of sound is not perceived, } \\
\text { unclear demonstration }\end{array}$ \\
$\begin{array}{l}\text { 4. No instant communication with the instructors, } \\
\text { lagging problem }\end{array}$ \\
$\begin{array}{l}\text { 5. Teachers are too busy with technical } \\
\text { manipulation without paying attention to the learner's } \\
\text { need }\end{array}$ \\
\hline
\end{tabular}

Observing from the result, it is significant to discover that $60 \%$ of the top five problems relate to the discomfort of audio experience. The rest $40 \%$ problems are communicative deficiency caused by technical issues. Notably, the online instrumental classes can not exactly follow the in-person teaching path that mostly is constructed by imitative behaviors due to the sound quality. To resolve the online lagging problem, sometimes the pre-recorded samples can help and reduce the waste of time. However, the duration of the samples should not be too long as the one-way presentation can easily be too redundant to be less attractive for the audience. Based on most students' experience, the fast speed of music playing often produces an unclear sonority, and slowing down the tempo of performance via the internet during the teaching-learning process is necessary. The experiments of where to locate the microphone and computer is also an important step for better sound receiving. Compared with the computer, the laptop is considerably more practical and handy for online instrumental classes. For a group class, the instructor can send students the backing soundtrack rather than asking them to play together through the internet.

\subsection{Interactive Aspect}

In addition to the technical aspect, the interaction between instructors and students deserve more discussion. The engaging management of online music courses requires a community and communication to stimulate the learner's enthusiasm and activeness. A good online environment is achieved by the creativity of social, cognitive, and teaching presences [12].To reinforce the teacher-learner relationship, a sustainable learning style of course design should contain the feedback from students to avoid isolation from one another. In fact, each learner has an individual way to assimilate and organize the knowledge or understanding, which makes the instructor act not only as a critical observer but also as a mentor in favor of a student's self-cultivation. In contrast with the traditional physical class, distance learning requires a stronger motivation from the learner as distance music learning incorporates the multimedia application of artistic resources. Thus, the instructor has to be sensitive to influential factors such as intelligence, personality, and culture of the student for an insight to develop one's learning interest to a greater extend.

\subsection{Problem-Based Learning (PBL)}

Problem-Based Learning has been applied in many fields as a teaching method that enables the learner to creatively promote reflective and critical thinking skills. The online instrumental class displays interdisciplinary feature that involves meaningful problems and impact that remain unresolved. To effectively make use of the internet sources, a teacher can conduct an online instrumental class by rising a central concept with a typical problem, encouraging the learner to seek out a deeper understanding of relevant music materials from a variety of online performing sources. In the process of solving a problem, students receive the opportunity of self-directed learning habit through practice and activity [13]. Meanwhile, it can develop a social interaction from a typical Problem-Based Learning setting when the student presents the reorganized experience of going 
beyond the teacher's assigned problem. The reflection of PBL learning can be thought-provoking to both educators and learners.

\section{CONCLUSION}

In summation, most online music programs in higher education mainly affiliate with music theory, music history, and music appreciation courses. Currently, the body of research on pedagogical strategies for music distance learning is still in its infancy. The effect of online instrumental classes can be elevated as long as we resolve the technical and interactive problem by establishing a reliable online learning experience that meets the standard of expectation. This article aims to propose pedagogical strategies from multiple perspectives of view for a more positive learning outcome from online instrumental classes. I hope this study will be a helpful resource presenting suggestions for a more positive outcome of online instrumental lessons, and it can inspire further advanced research on the relevant subjects.

\section{REFERENCES}

[1] J.W. Gikandi, D. Morrow, N.E. Davis, Online formative assessment in higher education: A review of the literature. Comput. Educ. 57(4) (2011), 2333-2351. DOI: https://doi.org/10.1016/j.compedu.2011.06.004

[2] Semira Oncu, Hasan Cakir, "Research in online learning environments: Priorities and methodologies", Comput. Educ 57 (1) (2011), 2098-1108. DOI: https://doi.org/10.1016/j.compedu.2010.12.009

[3] G. Conole, M. Oliver, Contemporary Perspectives in e-Learning Research: Themes, Methods, and Impact on Practice, The open and flexible learning Series, New York, Routledge, 2007.

[4] Meilung Shih, Jui Feng, Chi-Chung Tsai,"Research and trends in the field of e-learning from 2001 to 2005: A content analysis of cognitive studies in selected journals", Comput. Educ 51 (2) (2008) 955-967.

DOI:https://doi.org/10.1016/j.compedu.2007.10.00 4

[5] F. J. Rees, D. A. Downs, "Interactive Television and Distance Learning", Music Educators Journal, 82(2) (1995) 21-25. DOI: https://doi.org/10.2307/3398864

[6] J. Gikandi, D. Morrow, N.E. Davis, “Online formative assessment in higher education: A review of the literature", Comput. Educ 57(4) (2011) 2333-2351. DOI: https://doi.org/10.1016/j.compedu.2011.06.004
[7] Carol Johnson, "Teaching music online: Changing pedagogical approach when moving to the online environment", London Review of Education 15(3) (2017) 439-456. DOI: https://doi.org/10.18546/LRE.15.3.08

[8] Timothy J. Groulx, Patrick Hernly, “Online master's degrees in music education: The growing pains of a tool to reach a larger community", Update: Applications of Research in Music Education 28 (2) (2010) 60-70. DOI: https://doi.org/10.1177/8755123310361765

[9] R.M. Palloff, K. Pratt, The Excellent Online Instructor: Strategies for professional Development, Jossey-Bass, 2011.

[10] L. Harasim, Learning Theory and Online Technologies, (2nd ed.) New York, Routledge, 2017.

[11] Meina Zhu, Annisa Sari, Mimi Miyoung Lee, "A systematic review of research methods and topics of the empirical MOOC literature (2014-2016)", Internet High Educ. 37 (2018) 31-39. DOI: https://doi.org/10.1016/j.iheduc.2018.01.002

[12] T. Anderson, L. Rourke, D.R. Garrison, W. Archer, "Assessing teaching presence in a computer conferencing context", Journal of Asynchronous Learning Networks, 5 (2) (2001) 1-17. DOI: http:// 10.24059/olj.v5i2.1875

[13] Elaine H. J. Yew, Karen Goh, "Problem-Based Learning: An Overview of its Process and Impact on Learning", Health Professions Education 2 (2) (2016)75-79. DOI: https://doi.org/10.1016/j.hpe.2016.01.004 